\title{
Criatividade e Clima Criativo entre Alunos de Escolas Abertas, Intermediárias e Tradicionais
}

\section{Criatividade no contexto escolar}

\author{
Daniela Rezende Matos \\ Denise de Souza Fleith
}

\section{Resumo}

Este estudo foi conduzido com o objetivo de investigar a criatividade e percepção do clima de sala de aula de alunos de escolas consideradas abertas, intermediárias e tradicionais. Participaram desta pesquisa 174 alunos, que cursavam a $4^{\text {a }}$ série do ensino fundamental, de oito escolas particulares de Brasília. Os resultados indicaram diferenças significativas entre alunos de escolas abertas, intermediárias e tradicionais somente em relação à fluência no subteste de criatividade Complementação de Figuras, bem como interação significativa entre gênero e tipo de escola em relação à dimensão originalidade no mesmo subteste. Em relação às medidas da percepção do clima de sala de aula, os resultados revelaram haver interação significativa somente entre gênero e tipo de escola para o fator Interesse do Aluno pela Aprendizagem.

Palavras-chave: Criatividade; Características da sala de aula: Meio escolar.

\section{Creativity and creativity climate among students from open, intermediary and traditional schools}

\begin{abstract}
This study was conducted aiming to investigate the creativity and perception of classroom creativity climate of students from open, intermediary and traditional schools. One hundred and seventy-four $4^{\text {th }}$ grade students from eight private schools in Brasilia participated in the study. The results indicated significant differences among students from open, intermediary and traditional schools regarding fluency in the creativity subtest Picture Complementation, as well as a significant interaction between gender and type of school in relation to the originality in the same test. About the perception of the classroom climate for creativity, the results revealed that there is a significant interaction between gender and type of school only regarding the factor Interest for the Student's Learning.

Keyword: Creativity; Classroom environment; School environment.

\section{Creatividad y clima creativo entre alumnos de escuelas abiertas, intermediarias y tradicionales}

\section{Resumen}

Este estudio ha sido dirigido con el objetivo de investigar la creatividad y percepción del clima en la clase de alumnos de escuelas consideradas abiertas, intermediarias y tradicionales. Han participado de esta investigación 174 alumnos de $4^{\circ}$ grado de educación primaria, de ocho escuelas privadas de Brasilia. Los resultados han indicado diferencias significativas entre los alumnos de escuelas abiertas, intermediarias y tradicionales apenas en relación a la fluidez en el sub-test de creatividad Complementación de Figuras, así como interacción significativa entre sexo y tipo de escuela en relación a la dimensión originalidad en el mismo sub-test. En relación a las medidas de la percepción del clima en la clase, los resultados han mostrado la existencia de una interacción significativa apenas entre sexo y tipo de escuela para el factor Interés del Alumno por el Aprendizaje.

Palabras clave: Creatividad; Características e clase, Medio escolar. 


\section{Introdução}

A relevância do ambiente escolar para o desenvolvimento do potencial criativo dos indivíduos é uma questão indiscutível. Sobre isso, Fleith (1994) enfatiza que a escola possui o importante papel de promover o desenvolvimento das habilidades criativas dos alunos, estimulando a exploração de temas interessantes, o exercício do pensamento crítico e divergente e a criação de uma atmosfera de sala de aula que valorize a expressão e produção de idéias.

Várias pesquisas, inclusive, têm comprovado a importância de um clima de sala de aula favorável a um melhor aprendizado e ao desenvolvimento da criatividade dos alunos (Brookover \& cols., 1978; Fleith, 2000; Fraser, 1984; Marshall, 1981; Thomas \& Berk, 198I). Segundo Alencar e Fleith (2003), o esforço do individuo não é o bastante para o desenvolvimento do seu potencial criador; o contexto social no qual ele está inserido desempenha papel determinante na estimulação das habilidades criativas.

Hasirci e Demirkan (2003) também discutem a relevância do ambiente escolar na promoção das habilidades criativas dos indivíduos. Esses autores destacam que qualquer compreensão de educação ou ambientes de aprendizagem pressupõe criatividade e que, portanto, os ambientes educacionais devem conter os componentes necessários ao seu desenvolvimento. Alencar e Fleith (2003), por exemplo, sugerem como estratégias de ensino propiciadora de uma atmosfera criativa em sala de aula oferecer feedback informativo, incentivar e orientar os alunos a buscar informações adicionais sobre assuntos de seu interesse, divulgar o trabalho realizado pelos alunos, relacionar o conhecimento ensinado ao cotidiano dos alunos, abordar assuntos que sejam conectados entre si e despertem o interesse dos alunos e cultivar o senso de humor.

Um outro foco dos estudos que tem sido amplamente investigado se refere à percepção de professores e estudantes quanto à organização e/ou clima de sala de aula para criatividade (Brunetti, Cohen, Meyer \& Molnar, 1972; Darom \& Rich, 1988; Fleith, 2000; Johnson \& Johnson, 1999). A maioria desses estudos tem encontrado diferenças entre as percepções de professores e estudantes quanto ao clima de sala de aula, sendo que a percepção de professores tem se mostrado mais positiva do que a dos alunos.

Levando-se em consideração a grande influência exercida pelo contexto educacional no desenvolvimento da criatividade, além do importante papel desempenhado pela escola na promoção do potencial criador, optou-se neste estudo por comparar escolas que trabalham com diferentes tipos de metodologias de ensino, chamadas nessa pesquisa de escolas abertas, intermediárias e tradicionais, em relação à criatividade e percepção do clima de sala de aula por parte do aluno.

\section{Descrição de Escolas Abertas, Intermediárias e Tradicionais}

O movimento da "escola aberta", segundo Virgolim e Alencar (1993), surgiu no Pós-Guerra, primeiramente na Inglaterra e depois nos Estados Unidos, com o objetivo de provocar uma ampla mudança no cenário educacional vigente e, conseqüentemente, uma reformulação nos princípios da escola tradicional. Porém ganhou força apenas a partir da década de 70. Este movimento foi criado com o objetivo de promover condições que possibilitassem uma aprendizagem mais significativa, bem como o exercício e desenvolvimento das habilidades criativas dos alunos. Considerava-se que o modelo tradicional de ensino vigente não estava oferecendo aos alunos oportunidades de construção do conhecimento (Amabile, 1989).

Desde então, várias pesquisas foram conduzidas a fim de verificar a eficácia desse tipo de pedagogia em relação à criatividade, autoconceito, habilidade social, realização acadêmica, dentre outras variáveis. Porém, vários pesquisadores têm destacado a enorme dificuldade em se estudar a "escola aberta" em função da variabilidade de definições existentes para esse termo (Amabile, 1989; Horwitz, I979; Kohl, 1975; Virgolim \& Alencar, 1993). Kohl (1975), um dos precursores da escola aberta, aponta que realmente é difícil saber exatamente o que vem a ser uma sala de aula aberta, mas, apesar disso, é fundamental que não se confunda este tipo de escola com um ambiente permissivo. Apesar da escola aberta ter várias 
definições possíveis, Amabile (1989) destaca que geralmente esse tipo de pedagogia é caracterizado por oferecer uma atenção mais individualizada aos seus estudantes, ter uma estrutura mais flexível e menos direcionamento ao desempenho dos alunos.

Virgolim e Alencar (1993) concluem, por um lado, que há concordância entre autores em relação às concepções básicas da escola aberta no tocante ao aprendizado se dar por meio da interação com o ambiente, o aluno ter independência nas escolhas relacionadas a sua própria aprendizagem, o desenvolvimento ocorrer de uma forma individualizada e variada, o processo de aprendizagem ser mais importante do que o produto e a educação ser centrada no aluno e no professor. Essas destacadas, no entanto, podem variar um pouco de país para país.

A escola tradicional, por outro lado, pode ser caracterizada, segundo Bernstein (citado por Nicolacida-Costa, 1987) como a que apresenta hierarquia e regras bastante claras e explícitas, possui professores controladores, oferece pouca liberdade de exploração aos alunos (carteiras dispostas em filas e voltadas para a mesa do professor), apresenta uma rigidez nos horários, faz clara separação entre os horários de estudo e recreio, privilegia a transmissão e reprodução de conhecimento e utiliza, principalmente, provas para averiguar a eficácia da transmissão de conhecimento.

Também Ramey e Piper (1974) descrevem a escola tradicional, em contraste com a escola aberta, apresentando como características bastante comuns a preocupação com provas e notas, autoridade excessiva do professor, ensino realizado em grupos maiores e currículo cuidadosamente elaborado e seguido com mínimas variações. Para esses autores, a escola tradicional enfatiza principalmente a obediência, a competência e o excesso de atividades escolares, além de seguir à risca um currículo previamente elaborado.

A escola intermediária é, por sua vez, aquela que apresenta algumas características próprias das escolas abertas e outras presentes nas escolas tradicionais. Ou seja, se considerarmos esses tipos de escolas em termos de um continuum, a escola intermediária, como o próprio nome sugere, estaria em uma posição mais central.
Para Thomas e Berk (198I), a escola intermediária considera que os conhecimentos são adquiridos de maneira formal e também na prática, as disciplinas são integradas entre si com o objetivo de se fazer conexões entre as diversas áreas do conhecimento, o desempenho acadêmico é considerado importante, mas não exclui outras contribuições e habilidades dos indivíduos, a avaliação inclui o progresso do aluno em relação ao seu próprio desenvolvimento e as decisões e regras estabelecidas em sala de aula são discutidas por alunos e professor. Há características tanto da escola tradicional quanto da aberta presentes e relativizadas nesse tipo de escola.

Comparando Escolas Abertas, Intermediárias e Tradicionais em Relação a Criatividade

Grigorenko (1999) obteve resultados divergentes ao comparar as habilidades analíticas, práticas e criativas de 333 estudantes, com idades entre 8 e 17 anos, de escolas abertas e tradicionais da Rússia. Os resultados indicaram que a escola aberta favorece mais o desenvolvimento das habilidades cognitivas dos estudantes do que as instituições tradicionais. Além disso, os alunos das escolas abertas apresentaram um nível de criatividade superior aos dos alunos das escolas tradicionais.

No Brasil, um interessante estudo sobre as habilidades do pensamento criativo dos alunos de escolas abertas, intermediárias e tradicionais foi conduzido por Virgolim e Alencar (1993). Nessa pesquisa, as autoras investigaram o nível de criatividade de 438 alunos de $3^{\mathrm{a}}$ e $4^{\mathrm{a}}$ séries do ensino fundamental dos três tipos de escolas, a partir da utilização da Bateria Torrance de Pensamento Criativo. Os resultados encontrados apontaram diferenças significativas a favor dos alunos do gênero feminino, em contraste com os do gênero masculino, e superioridade dos alunos da escola intermediária em relação a essa variável quando comparados aos das demais escolas.

Em uma revisão realizada por Horwitz (1979), os estudos que examinaram o nível de criatividade entre escolas abertas e tradicionais apresentam resultados pouco consistentes. Dentre 33 estudos analisados, apenas 12 revelaram superioridade da escola aberta para desenvolver as habilidades criativas dos seus 
alunos, ao passo que 10 estudos mostraram resultados contraditórios e II não encontraram diferenças significativas entre os dois tipos de escola quanto à criatividade. É relevante ressaltar que nenhum estudo revisado apontou prevalência da escola tradicional sobre a escola aberta na promoção da criatividade dos seus alunos.

Pode-se notar que inúmeras pesquisas foram conduzidas no sentido de investigar diferenças em relação à criatividade de estudantes de escolas abertas, intermediárias e tradicionais. Entretanto, os dados não são conclusivos a favor de uma ou outra pedagogia. Amabile (1989) destaca que grande parte dos estudos realizados antes da metade da década de 70 aponta para a supremacia das escolas abertas em relação às escolas tradicionais quanto ao desenvolvimento da criatividade. Por outro lado, a maioria dos estudos realizados após esta data aponta pequenas diferenças entre esses tipos de escolas. Conclui-se, portanto, que é necessário investigar o tema a fim de se construir dados que sejam mais precisos no sentido de fornecer subsídios a projetos pedagógicos e outras ações de ensino elaborados e implementados nas escolas brasileiras.

Alem disso, Virgolim e Alencar (1993) chamam atenção para o fato de que no Brasil, apesar de inúmeros estudos terem sido conduzidos com vistas a examinar o desenvolvimento do fenômeno criativo no contexto educacional (Alencar, 2000; Alencar \& Fleith, 2004a; 2004b; Borges, 1997; Carvalho, 2004; Fleith, 1994, 200I), muito pouco foi investigado a cerca da influência que um contexto de ensino aberto pode ter sobre a criatividade dos seus alunos. Isso pode ser explicado em função de problemas metodológicos decorrentes de uma ausência de definição universal para os construtos investigados ou mesmo em função de uma mudança de metodologia de ensino nas escolas tradicionais. Vale salientar que os dados descritos por Amabile (1989) dizem respeito a escolas americanas e talvez não representem o cenário educacional de países em desenvolvimento, como o Brasil.

Neste sentido, o presente estudo foi desenvolvido com os objetivos deinvestigar a criatividade e percepção do clima de sala de aula entre alunos de $4^{\mathrm{a}}$ série do ensino fundamental de escolas abertas, intermediárias e tradicionais de Brasília; examinar a criatividade e percepção do clima de sala de aula entre alunos do gênero masculino e feminino.

\section{Método}

\section{Participantes}

Participaram desta pesquisa 174 alunos, que cursavam a $4^{\text {a }}$ série do ensino fundamental, de oito escolas particulares classificadas como aberta, intermediária ou tradicional, localizadas no Plano Piloto de Brasília. Os alunos eram provenientes de nível sócio-econômico médio e médio-alto.

A idade média dos participantes do estudo era de 9,82 anos, variando entre 9 e 13 anos. Do total de alunos participantes, 84 eram do gênero masculino $(48,3 \%)$ e 90 do gênero feminino $(51,7 \%)$. Em relação ao número de alunos participantes matriculados em cada tipo de escola, 74 alunos (42,5\%) eram de escolas abertas, 53 (30,5\%) de escolas intermediárias e 47 (27\%) eram de escolas tradicionais.

A seleção da amostra se deu por conveniência, em função de não haver, no Brasil, instrumentos que agrupem escolas de acordo com o tipo de pedagogia aplicada. Tampouco existe uma classificação oficial das escolas de acordo com o tipo de pedagogia empregada. Optou-se por incluir na pesquisa alunos que já estavam matriculados na escola investigada há pelo menos um ano, uma vez que esses alunos já estariam mais adaptados ao tipo de pedagogia utilizado na instituição. Esse critério para a seleção da amostra também foi usado no estudo realizado por Virgolim e Alencar (1993) acerca da criatividade, autoconceito e atitudes com relação à escola entre alunos de escolas abertas, intermediárias e tradicionais.

\section{Procedimento para escolha e classificação das escolas}

Inicialmente foi feito contato com algumas escolas particulares do Plano Piloto com o objetivo de selecionar os três tipos de escolas exigidos para este estudo. No primeiro contato telefônico, foi agendada uma reunião com a diretora a fim de explicar os 
motivos da pesquisa, bem como os procedimentos que seriam adotados para a sua realização. Após a explicitação dos objetivos da pesquisa e concessão da autorização por parte da escola para a realização do estudo, foi encaminhada uma carta aos pais dos alunos, descrevendo os objetivos da pesquisa e solicitando autorização para a participação de seus filhos nesse estudo. Após a autorização por escrito dos pais iniciouse a coleta de dados. Duas escolas convidadas recusaram-se a participar do estudo.

Foram selecionadas oito escolas para participar do estudo, levando-se em conta o tipo de metodologia utilizada em cada uma e o enquadramento nos vários critérios apontados pela literatura para diferenciar os tipos de escolas. Os critérios utilizados para a classificação das escolas em abertas, intermediárias e tradicionais foram o tipo de metodologia que a escola segue, os princípios norteadores de sua pedagogia, a organização do espaço físico da escola, a estruturação do horário, os critérios utilizados para avaliar o aprendizado do aluno, as atividades desenvolvidas e o tipo de material utilizado pelos alunos (Nicolaci-daCosta, 1987; Virgolim \& Alencar, 1993). Essas informações foram obtidas mediante entrevista semiestruturada com o coordenador pedagógico ou diretor de cada escola.

Além disso, cada escola apresentou folhetos informativos de divulgação à comunidade para complementação das informações obtidas na entrevista. Todas essas informações permitiram traçar o perfil de cada uma das escolas selecionadas. Para a classificação das escolas, foi realizada uma análise do conjunto de critérios presentes na literatura, uma vez que, nenhuma das escolas investigadas se encaixava perfeitamente no perfil descrito na literatura. A partir da análise de cada escola, optou-se por classificar como aberta aquela que apresentasse pelos menos três características específicas deste tipo de escola, como por exemplo, organização flexível do espaço físico, forma de avaliação diversificada, tipo de material utilizado pelo aluno, diversidade de materiais disponíveis em sala de aula.

Já uma escola denominada intermediária seria aquela que apresentasse características tanto da escola aberta quanto da tradicional. Ao lado disso, uma escola classificada como tradicional deveria apresentar pelo menos três características deste tipo de escola, tais como, uso exclusivo de provas na avaliação do aluno, pouca diversidade de materiais e atividades desenvolvidas.

De acordo com essa classificação, três escolas foram consideradas "abertas", três "intermediárias" e duas escolas foram consideradas "tradicionais". A fim de garantir uma maior fidedignidade na classificação das escolas participantes do estudo foi solicitado a um grupo de juízes, professores, alunos de graduação e pós-graduação envolvidos em projeto de pesquisa na área de Psicologia Educacional que classificassem as escolas como abertas, intermediárias e tradicionais. Para isto foi apresentado uma descrição detalhada de cada escola, bem como uma definição dos tipos de escola. Houve concordância entre a classificação proposta pela pesquisadora e pelo grupo de juízes.

\section{Instrumentos}

\section{Testes Torrance de Pensamento Criativo -} TTCT.

Quatro subtestes dos Testes Torrance do Pensamento Criativo TTCT - (forma A) foram utilizados nesta pesquisa, sendo dois de natureza verbal e dois de natureza figurativa (Torrance, 1974). O TTCT foi inicialmente publicado na década de 60 e desde então revisado (Torrance, 1990). Foram avaliadas três características do pensamento criativo que são definidas como fluência, o número de respostas e soluções diferentes que os alunos fornecem a uma situação-problema; flexibilidade, o número de diferentes categorias de idéias ou formas diferentes de enfrentar uma situação-problema; e originalidade, que seria a capacidade de produzir idéias raras ou incomuns, estatisticamente infreqüentes.

Os dois subtestes verbais utilizados no estudo foram Aperfeiçoamento do Produto, no qual os alunos deveriam listar maneiras diferentes e interessantes de melhorar um elefante de brinquedo de forma que as crianças pudessem se divertir mais com ele e Usos Diferentes para uma caixa de papelão, em que os alunos gerararam usos variados e originais para uma caixa de papelão. Os dois subtestes figurativos utilizados foram Completando Figuras, no qual os alunos traçaram linhas às figuras incompletas a fim de produzir desenhos 
diferentes e interessantes, bem como inventar títulos aos desenhos produzidos e Linhas, no qual os alunos produziram desenhos utilizando pares de linhas retas que são apresentados. Cada subteste foi realizado no período máximo de 10 minutos.

As respostas foram avaliadas seguindo as normas constantes do manual do instrumento (Torrance, 1990). A fluência foi avaliada com base no número de respostas relevantes em cada subteste. Para o levantamento da flexibilidade, identificou-se o número total de categorias diferentes em que as respostas dadas pelos alunos foram classificadas. Com relação à originalidade, foi atribuído valor de zero a dois pontos para cada resposta, de acordo com a raridade estatística da mesma (Alencar, Fleith, Shimabukuro \& Nobre, 1987).

O escore de criatividade verbal para cada aluno foi obtido por meio da soma dos escores de fluência, flexibilidade e originalidade obtidos nos dois subtestes de natureza verbal. $O$ mesmo se deu para o escore de criatividade figurativa. Obteve-se ainda um escore de criatividade total, fruto da soma dos escores de criatividade verbal e figurativa.

Quanto à validade e fidedignidade do Teste Torrance de Pensamento Criativo, Torrance (1974) obteve coeficientes de fidedignidade do tipo teste-reteste variando entre 0,60 a 0,93 para os vários subtestes. Estes dados foram obtidos com uma amostra de estudantes universitários que responderam ao instrumento em dois momentos com um intervalo de três meses. Vários estudos (Cropley, 1972; Torrance, 1972) forneceram evidência da validade do TTCT. Segundo Torrance (1988), a evidência mais forte de que existe uma relação entre o desempenho no teste e realização criativa na vida real foi obtida por meio de pesquisas longitudinais. Os resultados destes estudos mostram que os escores do TTCT estavam correlacionados com as realizações na vida adulta. Os coeficientes de correlação obtidos foram de 0,59 para homens e 0,46 para mulheres (indivíduos acima de 12 anos) e 0,5 I e 0,49 (indivíduos acima de 20 anos). A escolha do Teste Torrance de Pensamento Criativo neste estudo deve-se ao fato deste ser o teste mais citado na bibliografia da área, sendo usado amplamente por pesquisadores de diversas partes do mundo, inclusive no Brasil (Borges, 1997; Mendonça, 2003; Wechsler, 2002).

\section{Escala sobre Clima para a Criatividade em Sala de Aula (Fleith \& Alencar, 2005)}

Esta escala composta de 22 itens identifica fatores associados à criatividade em sala de aula, segundo a percepção de alunos de $3^{\mathrm{a}}$ e $4^{\mathrm{a}}$ séries do ensino fundamental. Uma escala de freqüência de 5-pontos é utilizada para a resposta aos itens: (I) nunca, (2) poucas vezes, (3) algumas vezes, (4) muitas vezes e (5) sempre. A validade de construto da escala foi verificada por meio da análise fatorial exploratória da sua estrutura interna.

Cinco fatores são medidos por esta escala: Suporte da professora à Expressão de Idéias do Aluno (Fator I), Autopercepção do Aluno com Relação à Criatividade (Fator 2), Interesse do Aluno pela Aprendizagem (Fator 3), Autonomia do Aluno (Fator 4) e Estímulo da Professora à Produção de Idéias do Aluno (Fator 5). Cinco itens compõem o Fator I (ex.: a professora dá atenção às minhas idéias, eu tenho chance de participar de várias atividade); quatro itens compõem o Fator 2 (ex.: eu me acho criativo, eu uso a minha imaginação); seis itens compõem o Fator 3 (ex.: os trabalhos que faço são divertidos, eu gosto da matéria ensinada), quatro itens compõem o Fator 4 (ex.: eu procuro fazer as tarefas de maneiras diferentes, eu posso escolher o que quero fazer) e três itens compõem o Fator 5 (ex.: a professora me pede para pensar em novas idéias). Os coeficientes alfa de fidedignidade obtidos foram: 0,73 para o fator I; 0,65 para o fator 2; 0,66 para o fator 3; 0,55 para o fator 4; e 0,58 para o fator 5 . A correlação item total variou de 0,30 a 0,58 .

\section{Procedimento}

Após a realização de todos os procedimentos formais junto à direção da escola, agendou-se o dia e horário para aplicação dos instrumentos de modo a não prejudicar as atividades de cada professor. Os instrumentos foram, em seguida, aplicados de forma coletiva em duas etapas distintas. Na primeira, foram aplicados dois subtestes (um de natureza verbal e um figurativa) da Bateria Torrance de Pensamento Criativo. 
Na segunda etapa, geralmente realizada uma semana após a primeira, foram aplicados os dois outros subtestes da Bateria Torrance de Pensamento Criativo. A aplicação do teste de criatividade foi realizada conforme instruções constantes do manual. Em seguida os alunos responderam à Escala sobre Clima para a Criatividade em Sala de Aula. A aplicação deste instrumento levou em média 10 minutos. Todos os instrumentos foram aplicados pela primeira autora deste trabalho.

\section{Resultados}

Os resultados quanto à criatividade entre alunos de escolas abertas, intermediárias e tradicionais indicaram diferenças significativas somente em relação à fluência na atividade Complementação de Figuras $(F$ $[2,162]=3,502 ; p<0,032)$ (Tabela I). O teste de Scheffé foi usado como post hoc e apontou o desempenho superior dos alunos de escolas abertas $(M=9,13 ; D P=1,79)$ em comparação aos das escolas intermediárias $(M=8, I 8 ; D P=2,36)$. Não foram observadas diferenças significativas entre alunos dos três tipos de escolas nas demais medidas de criatividade. Os resultados indicaram não haver diferenças significativas entre os alunos do sexo masculino e feminino em relação à criatividade.

Os resultados indicaram, ainda, haver interação significativa entre tipo de escola e gênero em relação à dimensão originalidade do subteste Comple-

Tabela I. Média, Desvio-Padrão, Valor F nas Medidas de Criatividade de Alunos de Escolas Abertas, Intermediárias e Tradicionais

\begin{tabular}{|c|c|c|c|c|c|c|c|c|c|}
\hline \multirow[b]{2}{*}{ Criatividade } & & Escola & Aberta & Escola & Interm. & Escola & Trad. & \multirow[t]{2}{*}{$F$} & \multirow[t]{2}{*}{$p$} \\
\hline & & $\bar{M}$ & $D P$ & $M$ & $\overline{D P}$ & $M$ & $\overline{D P}$ & & \\
\hline Linhas & Flu & 10,70 & 4,41 & 9,88 & 4,73 & 9,93 & 5,95 & 0,488 & 0,615 \\
\hline \multirow[t]{2}{*}{ Paralelas } & Flex & 8,26 & 2,93 & 7,61 & 3,11 & 7,37 & 3,57 & 0,932 & 0,396 \\
\hline & Orig & 11,96 & 5,68 & 12,02 & 6,78 & 11,28 & 7,48 & 0,164 & 0,849 \\
\hline Usos & Flu & 16,48 & 9,15 & 17,55 & 10,63 & 17,85 & 10,50 & 0,202 & 0,818 \\
\hline \multirow[t]{2}{*}{ Inusuais } & Flex & 8,25 & 3,21 & 8,65 & 3,58 & 7,89 & 2,79 & 0,955 & 0,387 \\
\hline & Orig & 15,97 & 11,64 & 18,06 & 13,57 & 17,74 & 14,41 & 0,520 & 0,595 \\
\hline Completar & Flu & 9,13 & 1,79 & 8,18 & 2,36 & 9,02 & 2,06 & 3,502 & 0,032 \\
\hline \multirow[t]{2}{*}{ Figuras } & Flex & 7,56 & 1,72 & 6,75 & 2,35 & 7,61 & 2,56 & 2,320 & 0,102 \\
\hline & Orig & 11,25 & 3,09 & 10,88 & 4,09 & 11,37 & 3,61 & 0,321 & 0,726 \\
\hline Aperfeiçoar & Flu & 10,42 & 5,37 & 10,47 & 5,41 & 11,63 & 6,59 & 0,802 & 0,450 \\
\hline \multirow[t]{2}{*}{ Produto } & Flex & 5,18 & 2,28 & 5,16 & 1,99 & 5,39 & 2,17 & 0,058 & 0,944 \\
\hline & Orig & 13,61 & 8,33 & 13,20 & 8,61 & 13,67 & 9,38 & 0,056 & 0,945 \\
\hline Criatividade & & 65,97 & 32,57 & 70,32 & 34,50 & 72,60 & 35,37 & 0,533 & 0,588 \\
\hline \multicolumn{10}{|l|}{ Verbal } \\
\hline Criatividade & & 55,64 & 17,16 & 53,23 & 18,25 & 55,38 & 19,26 & 0,223 & 0,800 \\
\hline \multicolumn{10}{|l|}{ Figurativa } \\
\hline Criatividade & & 121,61 & 44,32 & 123,55 & 46,50 & 127,98 & 46,29 & 0,218 & 0,805 \\
\hline Geral & & & & & & & & & \\
\hline
\end{tabular}

Nota. Flu=Fluência, Flex=Flexibilidade, Orig=Originalidade. 
mentação de Figuras $(\mathrm{F}[2,162]=5,05 ; p<0,007)$. Os alunos do gênero masculino da escola aberta $(M=11,95 ; D P=3,28)$ obtiveram desempenho superior em relação aos do gênero feminino $(M=10,41 ; D P=2,64)$ do mesmo tipo de escola. Por outro lado, as alunas da escola intermediária $(M=12,07 ; D P=3,88)$ apresentaram desempenho superior aos alunos $(M=9,54 ; D P=3,97)$ deste tipo de escola. Não foram encontradas interações significativas entre gênero e tipo de escola em relação às demais variáveis de criatividade.

Com relação à percepção do clima de sala de aula, os resultados indicaram não haver diferenças significativas entre alunos de escolas abertas, intermediárias e tradicionais para os fatores medidos pela Escala sobre o Clima para a Criatividade em Sala de Aula (Tabela 2). Os resultados indicaram que não há diferenças significativas entre os alunos do gênero masculino e os alunos do gênero feminino em relação às medidas da percepção do clima de sala de aula.

Além disso, os resultados obtidos revelaram haver interação significativa entre gênero e tipo de escola em relação à percepção dos alunos acerca do clima de sala de aula em relação ao Fator 3 (Interesse do Aluno pela Aprendizagem) $(\mathrm{F}[2,164]=3,744$; $p<0,026)$. Os alunos da escola tradicional avaliaram mais satisfatoriamente o clima de sala de aula em relação ao Interesse do Aluno pela Aprendizagem $(M=4,36 ; D P=0,47)$ quando comparados às alunas do mesmo tipo de escola $(M=3,8 I ; D P=0,75)$. Por outro lado, as alunas da escola aberta $(M=4,15$; $D P=0,46)$ apresentaram avaliação mais positiva desta dimensão do clima de sala de aula em relação aos seus colegas do gênero masculino $(M=4, \mid 4 ; D P=0,63)$ (Tabela 3). Para os demais fatores acerca da percepção do clima de sala de aula não foram encontradas interações entre gênero e tipo de escola.

Tabela 2 - Média, Desvio-Padrão e Valor F nas Medidas de Percepção do Clima de Sala de Aula de Alunos de Escolas Abertas, Intermediárias e Tradicionais

$\begin{array}{lllll}\text { Aberta } & \text { Intermediária } & \text { Tradicional } & F\end{array}$

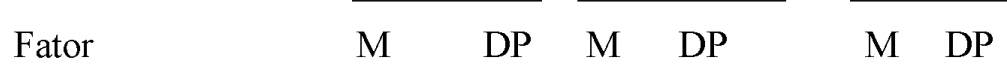

$\begin{array}{lllllllll}\text { Suporte da professora } & 3,85 & 0,61 & 3,97 & 0,84 & 3,77 & 0,61 & 0,915 & 0,40\end{array}$

à expressão de idéias

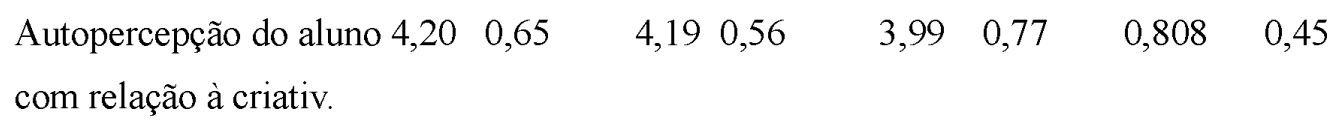

Interesse do aluno $\quad 4,15 \quad 0,56 \quad 4,10 \quad 0,57 \quad 4,00 \quad 0,71 \quad 0,180 \quad 0,84$

pela aprendizagem

\begin{tabular}{|c|c|c|c|c|c|c|c|}
\hline $\begin{array}{l}\text { Autonomia do } \\
\text { aluno }\end{array}$ & 2,85 & 0,73 & $2,99 \quad 0,75$ & 2,69 & 0,74 & 1,442 & 0,24 \\
\hline $\begin{array}{l}\text { Estímulo do professor à } \\
\text { produção de idéias }\end{array}$ & 3,78 & 0,86 & $3,50 \quad 0,85$ & 3,56 & 0,89 & 1,622 & 0,20 \\
\hline
\end{tabular}


Tabela 3 - Média, Desvio-Padrão nas Medidas de Percepção do Clima de Sala de Aula por Tipo de Escola e Gênero

\begin{tabular}{|c|c|c|c|c|c|c|c|}
\hline \multirow[b]{2}{*}{ Fator } & \multirow[b]{2}{*}{ Gênero } & \multicolumn{2}{|c|}{ Esc. Aberta } & \multicolumn{2}{|c|}{ Esc. Intermediária } & \multicolumn{2}{|c|}{ Esc. Tradicional } \\
\hline & & M & DP & M & DP & M & DP \\
\hline Suporte da & masculino & 3,83 & 0,67 & 3,87 & 0,74 & 3,79 & 0,54 \\
\hline $\begin{array}{l}\text { professora à } \\
\text { expressão de } \\
\text { idéias }\end{array}$ & feminino & 3,89 & 0,55 & 4,07 & 0,94 & 3,77 & 0,65 \\
\hline Autopercepção & masculino & 4,29 & 0,60 & 4,10 & 0,55 & 4,21 & 0,67 \\
\hline $\begin{array}{l}\text { do aluno com } \\
\text { relação à criat. }\end{array}$ & feminino & 4,09 & 0,69 & 4,28 & 0,57 & 3,87 & 0,80 \\
\hline Interesse do & masculino & 4,14 & 0,63 & 4,06 & 0,60 & 4,36 & 0,45 \\
\hline $\begin{array}{l}\text { aluno pela } \\
\text { aprendizagem }\end{array}$ & feminino & 4,15 & 0,46 & 4,13 & 0,55 & 3,81 & 0,75 \\
\hline Autonomia do & masculino & 2,93 & 0,75 & 2,95 & 0,74 & 2,86 & 0,57 \\
\hline aluno & feminino & 2,76 & 0,71 & 3,03 & 0,78 & 2,61 & 0,81 \\
\hline Estímulo da & masculino & 3,85 & 0,90 & 3,62 & 0,76 & 3,60 & 1,06 \\
\hline $\begin{array}{l}\text { professora à } \\
\text { produção de } \\
\text { idéias }\end{array}$ & feminino & 3,69 & 0,81 & 3,38 & 0,93 & 3,54 & 0,78 \\
\hline
\end{tabular}

\section{Discussão}

Os resultados obtidos com esse estudo apontam para o desempenho superior da escola aberta em relação à intermediária em apenas uma medida de criatividade (fluência no subteste figurativo “Complementação de Figuras"). Os resultados também indicaram haver interação significativa entre tipo de escola e gênero na medida originalidade do subteste de natureza figurativa "Complementação de Figuras". Os alunos do gênero masculino da escola aberta obtiveram um desempenho superior aos do gênero feminino desta escola nesta medida. Por outro lado, os alunos do gênero feminino da escola intermediária obtiveram um desempenho superior aos alunos do gênero masculino deste tipo de escola nesta medida de originalidade.

Uma possível explicação para este resultado é que os alunos do gênero masculino da escola aberta seriam mais estimulados a desenvolver a sua imaginação sem receio de serem repreendidos do que os alunos do gênero feminino. Por outro lado, as alunas da escola intermediária podem se sentir mais à vontade neste tipo de contexto escolar para exercitar a sua imaginação e criar objetos fora do comum, enquanto que os alunos deste tipo de escola poderiam se sentir mais inibidos e restritos a elaboração de desenhos mais comuns. Provavelmente, os alunos do gênero 
masculino precisariam de um ambiente escolar mais livre e sem excesso de controle para que pudessem desenvolver mais amplamente a sua imaginação, ao passo que os alunos do gênero feminino necessitariam de um ambiente mais estruturado e com poucas regras a fim de desenvolver mais adequadamente suas habilidades.

Neste estudo não foram identificadas outras diferenças significativas entre os alunos de escolas abertas, intermediárias e tradicionais em relação às demais medidas do pensamento criativo da Bateria Torrance. Estes dados corroboram os resultados obtidos no levantamento realizado por Horwitz (1979), em que dos 33 artigos revisados, I I revelaram não haver diferenças significativas entre esses tipos de escola quanto à criatividade.

Uma hipótese para explicar este resultado é a de que a criatividade passou a ser uma habilidade muito valorizada pela sociedade e, conseqüentemente, há uma exigência de que o ambiente escolar propicie o desenvolvimento desta (Strom \& Strom, 2002). Com isso, todos os tipos de escola estão procurando estimular e exercitar de alguma forma o potencial criativo de seus alunos a fim de formar cidadãos mais críticos e preparados para o mercado de trabalho. $O$ que diferencia as escolas é somente a maneira como essa criatividade é desenvolvida.

No estudo realizado por Virgolim e Alencar (1993), nota-se a superioridade da escola intermediária sobre os demais tipos de escola na maioria das medidas de criatividade. Neste estudo, realizado quase quinze anos depois, não foram observadas diferenças significativas entre os tipos de escola na maioria das medidas de criatividade.

Isso pode ser explicado em função da evolução do conceito de escola aberta. Esta nova pedagogia surgiu na década de 70 com o objetivo de oferecer uma alternativa às praticas educacionais autoritárias e rígidas existentes na época. Porém, ao longo dos anos a metodologia inicialmente proposta foi se modificando a fim de se adequar ao contexto de cada país e sociedade. Além disso, este tipo de escola precisou lidar com a expectativa dos pais de que seus filhos desenvolvessem uma série de habilidades importantes na vida, como criatividade, expressividade e senso crítico e, ao mesmo tempo, aprendessem o que eles aprenderam quando criança, como matemática e interpretação de texto (Nicolaci-da-Costa, 1986).

Diante disso, as metodologias de ensino de um modo geral passaram a buscar o desenvolvimento de atividades e a implementação de práticas educacionais que atendessem ao desejo dos pais do século $X X I$. Ou seja, nota-se, com este estudo que o desenvolvimento da criatividade entre os três tipos de escola é muito similar. Pode-se então, afirmar que o que difere é apenas a maneira como a criatividade do aluno é estimulada em sala de aula. É importante ressaltar, ainda, a relevância do contexto histórico influenciando os tipos de escola, ou seja, uma escola aberta na década de 70 apresenta características diferentes de uma escola aberta do ano 2000. Daí a necessidade de se tomar alguns cuidados com as comparações de estudos que foram realizados em tempos históricos distintos.

Em relação à percepção de clima de sala de aula, os resultados indicaram haver interação significativa entre tipo de escola e gênero para o fator Interesse do Aluno pela Aprendizagem. Os alunos do gênero feminino da escola intermediária avaliaram melhor o seu interesse pela aprendizagem do que os alunos do gênero masculino deste mesmo tipo de escola, ao passo que, os alunos do gênero masculino da escola tradicional avaliaram mais positivamente o seu interesse pela aprendizagem do que os alunos do gênero feminino desta escola. Papéis sexuais estereotipados parecem influenciar o clima da escola intermediária, uma vez que, os resultados indicam que as alunas avaliam melhor o seu interesse pela aprendizagem do que os alunos. Nota-se que indivíduos do gênero feminino são mais estimulados pelos seus pais e pela escola a ter uma postura mais responsável e de maior interesse pelo seu desenvolvimento acadêmico (Alencar, 1990). Porém na escola tradicional surpreendentemente, os resultados apontam o inverso. Isso pode ter ocorrido em função da escola não se preocupar com os estereótipos sexuais, uma vez que a polêmica divisão de papéis vem sendo bastante questionada, tendo assim os alunos do gênero masculino mais oportunidade de expressarem livremente o seu 
interesse pela aprendizagem. A escola tradicional parece estar investindo mais no desenvolvimento de valores e atitudes como o respeito, a ética e a cidadania, ao invés de buscar perpetuar mitos tão obsoletos.

Este estudo nos leva a concluir que é necessário haver uma sintonia entre o perfil do aluno e o tipo de escola em que ele estuda a fim de se obter o máximo de aproveitamento escolar, permitindo assim, o desenvolvimento de todas as suas habilidades e contribuindo para a formação holística do indivíduo. Neste sentido, não podemos apontar o melhor modelo de escola para o desenvolvimento do potencial criativo dos alunos. $O$ que deve ser considerado são as características e necessidades cognitivas, emocionais e sociais do aluno, seu ajustamento a determinados contextos escolares, bem como o perfil discente desejado em cada tipo de escola.

\section{Referências}

Alencar, E. M. L. S. (1990). Como desenvolver o potencial criador: um guia para a liberação da criatividade em sala de aula. Petrópolis, RJ: Vozes.

Alencar, E. M. L. S. (2000). O perfil do professor facilitador e do professor inibidor da criatividade segundo estudantes de pós-graduação. Boletim da Academia Paulista de Psicologia, 19, 84-94.

Alencar, E. M. L. S., Fleith, D. S., Shimabukuro, L. \& Nobre, M. A. (1987). Efeitos de um programa de treinamento de criatividade para professores do ensino de primeiro grau nas habilidades de pensamento criativo do aluno. Interamerican Journal of Psychology, 2 I , 56-7I.

Alencar, E. M. L. S. \& Fleith, D. S. (2003). Criatividade: múltiplas perspectivas ( $3^{\mathrm{a}}$.ed.). Brasília, DF: EdUnB.

Alencar, E. M. L. S. \& Fleith, D. S. (2004a). Inventário de práticas docentes que favorecem a criatividade no ensino superior. Psicologia Reflexão e Crítica, I7, I05-I I0.

Alencar, E. M. L. S. \& Fleith, D. S. (2004b). Creativity in university courses: Perceptions of professors and students. Gifted and Talented International, 19, 24-28.

Amabile, T. A. (1989). Growing up creative. Buffalo, NY: The Creative Education Foundation Press.
Borges, F. T. (1997). Habilidades de pensamento criativo em professores de escolas tradicionais e inovadoras. Dissertação de Mestrado, Universidade de Brasília, Brasília.

Brookover, W. B., Schweitzer, J. H., Schneider, J. M., Beady, C. H., Flood, P. K. \& Wisenbaker, J. M. (1978). Elementary school social climate and school achievement. American Educational Research Journal, 15, 301-318.

Brunetti, F. A., Cohen, E. G., Meyer, J. W. \& Molnar, S. R. F. (1972). Studies of team teaching in the open-space school. Interchange, 3, 85-101.

Carvalho, O. (2004). Elementos favorecedores e inibidores da criatividade na prática docente, segundo professores de geografia. Dissertação de Mestrado, Universidade Católica de Brasília, Brasília.

Cropley, A. J. (1972). A five-year longitudinal study of the validity of creativity tests. Developmental Psychology, 6, II9-124.

Darom, E. \& Rich, Y. ( 1988). Sex differences in attitudes toward school: Student self-reports and teacher perception. British Journal of Educational Psychology, 58, 350-355.

Fleith, D. S. (1994). Treinamento e estimulação da criatividade no contexto educacional. Em E. M. L. Alencar \& A. M. R. Virgolim (Orgs.), Criatividade: expressão e desenvolvimento (pp. I|3-|4I). Petrópolis, RJ: Vozes.

Fleith, D. S. (2000). Teacher and student perceptions of creativity in the classroom environment. Roeper Review, $22,148-153$

Fleith, D. S. (200I). Criatividade: novos conceitos e idéias, aplicabilidade à educação. Cadernos de Educação Especial, I7, 55-6I.

Fleith, D. S. \& Alencar, E. M. L. S. (2005). Escala sobre o clima para criatividade em sala de aula. Psicologia: Teoria e Pesquisa, 2 I (I), 85-9I.

Fraser, B. J. (1984). Differences between preferred and actual classroom environment as perceived by primary students and teachers. British Journal of Educational Psychology, 54, 336-339.

Gall, M. D., Borg, W. R. \& Gall, J. P. (1996). Educational research. An introduction (6 ${ }^{\mathrm{a}}$. ed.). New York, NY: Longman.

Grigorenko, E. L. (1999). Current trends in education in Russia: Preliminary outcomes indicative of students' cognitive development. International Journal of Psychology, 34, I75-184. 
Hasirci, D. \& Demirkan, H. (2003). Creativity in learning environments: The case of two sixth grade art-rooms. Journal of Creative Behavior, 37, I7-4I.

Horwitz, R. A. (1979). Psychological effects of the "Open Classroom”. Review of Educational Reserch, 49, 7I-86.

Kohl, H. (1975). Open classroom: a practical guide to a new way of teaching. London: Methuen.

Johnson, W. L. \& Johnson, A. M. (1999). Assessing perception of school climate among Jordanian students in Englishspeaking schools. Psychological Reports, 84, 395-397.

Marshall, H. H. (I98I). Open classrooms: Has the term outlived its usefulness. Review of Educational Research, 5I, |81-192.

Nicolaci-da-Costa, A. M. (1986). Família e pedagogia: nostalgia do tradicional ou carência do novo? Em S. A. Figueira (Org.), Uma nova família? O moderno e o arcaico na família de classe média brasileira. (pp.3 I-43) Rio de Janeiro,RJ: Zahar.

Nicolaci-da-Costa, A. M. (1987). Algumas reflexões sobre o controle da subjetividade nas novas e antigas pedagogias. Psicologia: Teoria e Pesquisa, 3, 25-34.

Ramey, C. T. \& Piper, V. (1974). Creativity in open and traditional classrooms. Child Development, 45, 557-560.

Strom, R. D. \& Strom, P.S. (2002). Changing the rules: Education for creative thinking. Journal of Creative Behavior, 36, 183-200.
Thomas, N. G. \& Berk, L. E. (198I). Effects of school environments on the development of young children's creativity. Child Development, 52, II53-I I62.

Torrance, E. P. (1972). Predictive validity of the Torrance Tests of Creative Thinking. The Journal of Creative Behavior, 6, 236-252.

Torrance, E. P. (1974). Torrance Tests of Creative Thinking. Norms-technical manual. Benseville, IL: Scholastic Testing Service.

Torrance, E. P. (1988). The nature of creativity as manifest in its testing. Em R. J. Sternberg (Org.), The nature of creativity (pp. 43-75). New York,NY: Cambridge University Press.

Torrance, E. P. (1990). Torrance Tests of Creative Thinking. Manual for scoring and interpreting results. Verbal, forms A and B. Bensenville, IL: Scholastic Testing Service.

Virgolim, A. M. R. \& Alencar, E. M. L. S. (1993). Habilidades de pensamento criativo entre alunos de escolas abertas, intermediárias e tradicionais. Psicologia: Teoria e Pesquisa, 9, 601-610.

Wechsler, S. M. (2002). Avaliação da criatividade por figuras e palavras. Testes de Torrance. Campinas,SP: Impressão Digital do Brasil.

Recebido em: 10/10 2005

Revisado em: 04/04/2006

Aprovado em: 18/06/2006

Sobre os autores:

Daniela Rezende Matos (danielarezande@zipmail.com.br) é mestre em Psicologia pela Universidade de Brasília

Denise de Souza Fleith (fleith@unb.br). Professora do Departamento de Psicologia Escolar e do Desenvolvimento do Instituto de Psicologia da Universidade de Brasília.

Endereço para correspondência:

Daniela Rezende Matos

SQS II 2 BI. C ap 306

CEP: 70910- 900 - Brasilia 